\title{
Is Underweight Associated with more Positive Body Image? Results of a Cross-Sectional Study in Adolescent Girls and Boys
}

\author{
Adam Kantanista, Magdalena Król-Zielińska, Joanna Borowiec and Wiesław Osiński \\ Poznan University of Physical Education (Poland)
}

\begin{abstract}
The aim of the study was to investigate the relationship between body image and prevalence of underweight, normal weight, and overweight in adolescents. The study included 1702 girls and 1547 boys, aged 14-16 years, who completed questionnaire assessing body satisfaction. The participants' BMI status: underweight, normal weight or overweight was determined on the basis of BMI cut-off values. Results revealed that more girls $(p<.001)$ showed low body satisfaction $(44.8 \%)$ and fewer girls $(p<.001)$ had high body satisfaction $(17.6 \%)$ compared to boys $(28.5 \%$ and $29.0 \%$, respectively). A two-way ANOVA revealed a significant interaction between BMI status and gender on body satisfaction $F(2,3243)=4.10, p=.017, \eta^{2}=.003$. In boys, body satisfaction was higher in normal weight and underweight in comparison to overweight individuals $(p<.001)$. Underweight girls presented higher body satisfaction than those who were normal weight and overweight $(p<.001)$. Our findings indicated that, in relation to gender, BMI status can be associated with different body satisfaction in adolescents. This should be taken into consideration when designing programs aimed at obesity and disordered eating prevention and body image improvement. Due to the fact that underweight girls and boys have high body satisfaction, this can lead to behaviors that maintain low body weight in adolescents and in turn this may have negative health consequences.
\end{abstract}

Received 22 January 2016; Revised 19 January 2017; Accepted 20 January 2017

Keywords: adolescents, body image, overweight, underweight.

Excessive body weight in adolescents has increased or is at least plateauing in many countries around the world (Ahluwalia et al., 2015). Young people who are obese are likely to be obese in adulthood (Freedman et al., 2005) and are therefore more at risk of heart disease, type 2 diabetes, stroke, several types of cancer, and osteoarthritis (U.S. Department of Health and Human Services, 2010). Less attention is paid to the issue of underweight; although, according to the studies, it affects from $5 \%$ to almost $12 \%$ of adolescents (Antal et al., 2009; Kantanista \& Osiński, 2014; Lazzeri et al., 2008). Compared to normal weight, underweight in adults was associated with increased all-cause mortality (Roh et al., 2014).

One of the factors linked to body weight is body image. Body image is a multidimensional construct that refers to how people think, feel, and behave with regard to their own physical attributes. Three facets of body image attitude can be examined: evaluation, affect, and investment (Muth \& Cash, 1997). Body image evaluation refers to individuals' satisfaction or dissatisfaction with their body and their evaluative beliefs

Correspondence concerning this article should be addressed to Adam Kantanista. Poznan University of Physical Education. 61-871. Królowej Jadwigi Street 27/39. Poznań (Poland). Phone: +48-618355204.

E-mail: adam.kantanista@gmail.com about it. Body image affect concerns feelings of anxiety, distress, and other emotions associated with the body. Body image investment refers to the cognitive, behavioral, and emotional importance of the body for self-evaluation (Cash, 2011; Muth \& Cash, 1997; Smolak, 2004).

Results from previous studies showed that body dissatisfaction is prevalent amongst adolescents. Wilkosz, Chen, Kenndey, and Rankin (2011) found that 24\% of girls and $22 \%$ of boys were dissatisfied with their bodies. Neumark-Sztainer, Story, Hannan, Perry, and Irving (2002) observed low levels of body satisfaction in $46 \%$ of girls and $6 \%$ of boys, while in overweight girls and boys, the prevalence of low level body satisfaction reached $59 \%$ and $48 \%$, respectively. Underweight girls have been shown to have higher body satisfaction in comparison to normal weight and overweight individuals, while underweight and overweight in boys were associated with lower body satisfaction (Kostanski, Fisher, \& Gullone, 2004; Zach et al., 2013).

Research on body image is important because the cult of body and beauty is one of the main concerns of adolescence (de Sousa, 2008). Lower body satisfaction has been shown to predict higher levels of dieting, unhealthy weight control behaviors and binge eating, lower levels of physical activity (Neumark-Sztainer, Paxton, Hannan, Haines, \& Story, 2006). On the other 
hand, it can be assumed that positive body satisfaction in underweight individuals can lead to unhealthy weight control behaviors to maintain low body mass status. To date, the association between body image and weight status has mainly been examined among normal weight and overweight adolescents. More research on body satisfaction that also includes underweight adolescents is still very much required. The aim of the study was to investigate the relationship between prevalence of underweight, normal weight, and overweight and body satisfaction in adolescents. Based on findings of previous research (e.g., Chen, Guo, Gong, \& Xiao, 2015; Kostanski et al., 2004; Muth \& Cash, 1997) we hypothesized that body satisfaction would be higher in normal weight adolescent boys and underweight adolescent girls in comparison to their peers with other BMI statuses.

\section{Method}

\section{Participants}

The study included a total of 3249 individuals, amongst them 1702 girls and 1547 boys aged 14-16 years old $\left(M_{\text {girls }}=15.05, S D=0.82, M_{\text {boys }}=15.10, S D=0.80\right)$ attending twelve junior high schools in the city of Poznań (Poland), which has a population of approximately 550,000. In girls, mean body height $(\mathrm{cm})$ was $164.0(S D=6.0)$, mean body weight $(\mathrm{kg})$ was 55.5 $(S D=9.8)$, and mean BMI $\left(\mathrm{kg} / \mathrm{m}^{2}\right)$ was $20.6(S D=3.3)$. In boys, mean body height $(\mathrm{cm})$, mean body weight $(\mathrm{kg})$, and mean BMI $\left(\mathrm{kg} / \mathrm{m}^{2}\right)$ were $173.0(S D=8.0), 61.8$ $(S D=12.6)$, and $20.6(S D=3.4)$, respectively. The sample was selected based on one-stage cluster sampling. Written assent from all participants and consent from parents or legal guardian were obtained. The protocol for the study was approved by the Local Bioethics Committee of Karol Marcinkowski University of Medical Sciences (decision no. 1068/07).

\section{BMI status}

Weight was measured with a Seca 761 scale in light clothing (without shoes) to the nearest $0.5 \mathrm{~kg}$, while height was measured with an anthropometer to the nearest $0.5 \mathrm{~cm}$. The body height and weight of participating girls and boys was determined and used to calculate body mass index (BMI), defined as the weight in kilograms divided by the square of the height in meters $\left(\mathrm{kg} / \mathrm{m}^{2}\right)$. On the basis of this latter parameter, three groups with different BMI status were created: a) underweight, b) normal weight, and c) overweight (this latter group also included individuals whose BMI corresponded to obesity). The qualification of participants into respective age- and gender-adjusted categories of body weight was based on the BMI cut-off values for children and adolescents proposed by Cole, Bellizzi, Flegal, and Dietz (2000) and Cole, Flegal, Nicholls, and Jackson (2007).

\section{Body image measure}

Body image was assessed using the Feelings and Attitudes Towards the Body Scale included in the Body Investment Scale developed by Orbach and Mikulincer (1998). Feelings and Attitudes towards the Body Scale comprises six statements (e.g., I like my appearance in spite of its imperfections, I am satisfied with my appearance, I feel comfortable with my body) each scored on a 5-item scale ranging from absolutely disagree to absolutely agree (corresponding to between 0 and 4 points). Some items were reverse-scored because positively worded and negatively worded items were used. Consequently, the global score ranged from 0 to 24 points. The higher the global score, the higher body satisfaction was. Raw scores were standardized as $T$-scores $(M=50, S D=10)$, and body satisfaction was presented in three categories (Kołoło, Guszkowska, Mazur, \& Dzielska, 2012): 0-14 points indicating low body satisfaction; $15-20$ points indicating moderate body satisfaction; and 21-24 points indicating high body satisfaction. In research conducted in Poland, the Feelings and Attitudes towards the Body Scale featured a high reliability with Cronbach's alpha reliability coefficient at .85 , and one factor accounting for $58 \%$ of total variance (Kołoło et al., 2012). In the present study, the scale's internal consistency established with Cronbach's alpha test was .91. In addition, metric invariance was tested earlier to assess whether girls and boys responded to the items from the Feelings and Attitudes towards the Body Scale in the same way. It was indicated that the measures were psychometrically invariant across girls and boys (Kantanista, Osiński, Borowiec, Tomczak, \& Król-Zielińska, 2015).

\section{Statistical analysis}

To compare the prevalence of the analyzed categories of variables in girls and boys a test for proportion was used. A two-way ANOVA was used to compare levels of body satisfaction (continuous, dependent variable) according to BMI status (categorical, independent variable: underweight, normal weight, overweight) and gender (categorical, independent variable: girls and boys) in adolescents. To determine the effect size for particular effects eta-squared $\left(\eta^{2}\right)$ was calculated. The Tukey's HSD post-hoc tests were used to compare body satisfaction between the subgroups with different BMI status among girls and boys. Statistical analysis was carried out using STATISTICA 10 software (Stat. Soft, Inc.). 


\section{Results}

The breakdown by BMI status, body satisfaction, and gender is included in Table 1 . Almost $75 \%$ of adolescents $(73.8 \%$ of girls and $76 \%$ of boys) had a normal body weight, $15.7 \%$ were overweight $(14.6 \%$ girls and $17.0 \%$ boys). More girls than boys were underweight $(11.6 \%$ and $7 \%$, respectively, $p<.001)$. More girls $(p<.001)$ showed low body satisfaction (44.8\%) and less girls $(p<.001)$ had high body satisfaction $(17.6 \%)$ compared to boys ( $28.5 \%$ and $29.0 \%$, respectively).

The results of the analysis of variance (ANOVA) of body satisfaction in adolescents depending on BMI status (underweight, normal weight, overweight) and gender (girls and boys) are shown in Figure 1. The interaction between BMI status and gender was significant $\left(F(2,3243)=4.10, p=.017, \eta^{2}=.003\right)$, as well as the effect of BMI status $\left(p<.001, \eta^{2}=.066\right)$ and gender $\left(p<.001, \eta^{2}=.021\right)$ separately.

Significant gender differences in terms of body satisfaction were found between normal weight $(p<.001)$ and overweight girls and boys $(p<.001)$ in post-hoc analyses. In girls, underweight participants showed the highest body satisfaction (16.8 points) and overweight individuals the lowest body satisfaction (10.8 points). The post-hoc tests confirmed that all subgroups of adolescent girls (categorized on the basis of BMI status) differed significantly in terms of body satisfaction at $p<.001$. Among boys, overweight individuals showed the lowest body satisfaction (14.1 points). Normal weight and underweight boys had similar levels of body satisfaction (respectively 17.7 points and 17.8 points). Post-hoc tests revealed that body satisfaction of normal weight or underweight individuals differed significantly when compared to overweight boys $(p<.001)$.

\section{Discussion}

The aim of the study was to analyze the relationship between prevalence of underweight, normal weight, and overweight and body image in adolescent females and males. Gender differences in body satisfaction were documented between girls and boys with different BMI statuses. Our hypotheses were confirmed, body satisfaction was higher in normal weight boys in comparison to overweight adolescent boys. Underweight girls presented higher body satisfaction than normalweight and overweight girls. This is in line with findings of other authors, who have observed that the BMI and gender were an important predictors of different body image aspects (Chen et al., 2015; Duncan, Al-Nakeeb, \& Nevill, 2013; Fenton, Brooks, Spencer, \& Morgan, 2010; Neumark-Sztainer, Goeden, Story, \& Wall, 2004; Zach et al., 2013). Eidsdottir, Kristjansson, Sigfusdottir, Garber, and Allegrante (2014) revealed an inverse relationship between BMI and body image, which was significantly stronger among older adolescent girls than boys.

The inverse relationship between BMI status and body satisfaction in girls found in the present study also corresponded with the findings of other authors (Neumark-Sztainer et al., 2002; Zach et al., 2013). For example, Neumark-Sztainer and colleagues (2002) found that the overweight and obese girls were more dissatisfied with their body than underweight and normal weight girls. Furthermore, according to Chen and colleagues (2015) overweight adolescent females had the highest body dissatisfaction levels, which was higher than normal-weight peers. Underweight girls had the lowest body dissatisfaction. The widespread tendency among girls of decreased body image satisfaction along with increasing BMI, is related to the prevalent cultural patterns that promote thin beauty ideals (Smolak, 2004). Additionally, during puberty girls experience physical changes in their bodies, including increases in the percentage of body fat (Wertheim \& Paxton, 2012). Adolescent girls often find themselves moving further from societal ideals that portray thinness as beautiful and desirable. An increasing discrepancy between the cultural ideal and girls' body mass or BMI often leads to negative body image (Fenton et al., 2010).

Table 1. Number of Girls and Boys Depending on the Prevalence of Underweight, Normal Weight, and Overweight and Prevalence of Low, Moderate, and High Body Satisfaction in 14- to 16-Year Old Girls and Boys

\begin{tabular}{|c|c|c|c|c|}
\hline & Overall $n(\%)$ & Girls $n(\%)$ & Boys $n(\%)$ & $p$ \\
\hline \multicolumn{5}{|l|}{ BMI status } \\
\hline Underweight & 305 (9.4\%) & $197(11.6 \%)$ & $108(7.0 \%)$ & $<.001$ \\
\hline Normal weight & $2433(74.9 \%)$ & $1257(73.8 \%)$ & $1176(76.0 \%)$ & .149 \\
\hline Overweight & $511(15.7 \%)$ & $248(14.6 \%)$ & $263(17.0 \%)$ & .061 \\
\hline \multicolumn{5}{|c|}{ Body Satisfaction } \\
\hline Low & $1203(37.0 \%)$ & $763(44.8 \%)$ & $440(28.5 \%)$ & $<.001$ \\
\hline Moderate & $1297(39.9 \%)$ & $639(37.6 \%)$ & $658(42.5 \%)$ & .004 \\
\hline High & 749 (23.1\%) & $300(17.6 \%)$ & $449(29.0 \%)$ & $<.001$ \\
\hline
\end{tabular}

Notes: $N=3249$ (1702 girls and 1547 boys). 


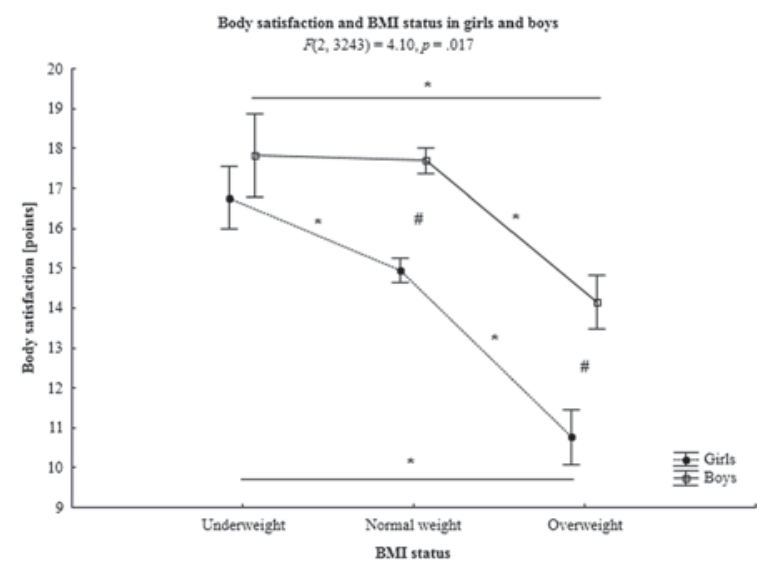

Figure 1. Results of two-way ANOVA of body satisfaction in relation to BMI status (underweight, normal weight, overweight) and gender in adolescents.

In the current study, underweight and normal weight boys had similar levels of body satisfaction and overweight boys had the lowest body satisfaction. Many authors noticed that body dissatisfaction could show a curvilinear relationship for BMI in boys and adult men (Chen et al., 2015; Muth \& Cash, 1997; Smolak, 2004). This could be related to the fact that underweight boys might be dissatisfied with their bodies because their muscles were too small (Eisenberg, Wall, \& NeumarkSztainer, 2012). Underweight boys often want to increase the size of their muscles. However, in our study, there was no statistical difference between the level of body satisfaction of underweight and normal weight boys. Also Chen and colleagues (2015) noted that underweight and normal-weight males had similar body dissatisfaction, which was significantly less than those of obese males. These results could be related to the general tendency found amongst boys to be satisfied with their appearance (Hargreaves \& Tiggemann, 2006). It should be also taken into account that body image is a multidimensional construct, hence, our result could be related to factors that were not evaluated in our study, such as body composition, sport competences, musculature, appearance and other.

Our research revealed that both girls and boys with the highest BMI showed the lowest body satisfaction. This is in line with other researchers who have pointed out that low body satisfaction is highly prevalent in overweight and obese individuals. For example, Lubans and Cliff (2011) observed a negative relationship between body fat percentage and the perception of physical attractiveness in 15-year old boys and girls. Sabeti and Gorjian (2013) found that obesity in adolescent girls and boys was one of the main factors decreasing their body image and consequently their self-esteem. Neither overweight and obese adolescent girls nor boys meet social standards of beauty, based on low body fat percentage and moderately muscular body shape in males (Murnen \& Don, 2012), or thinness in females (Mikolajczyk et al., 2010).

In the present paper the high percentage of adolescents with low body satisfaction was alarming. Almost $45 \%$ of girls and $28.5 \%$ of boys presented low body satisfaction. Similar results were observed in a study by Neumark-Sztainer and colleagues (2004), where almost $46 \%$ of females and $26 \%$ of males presented low body satisfaction. Different results were reported by de Sousa (2008). However, the author evaluated body image using a single question in which the adolescents described themselves as "thin", "normal" or "fat". His research has shown that $30.3 \%$ of girls and $25.8 \%$ of boys assessed them self as "thin" or "fat". In our study more girls than boys had low body satisfaction. This is consistent with a longitudinal study of Holsen, Carlson Jones, and Skogbrott Birkeland (2012).

It should be noted, that body satisfaction is associated with many different factors. Some researchers have indicated that the main problem could be related to the interpretation of having weight different than the ideal (de Sousa, 2008). According to Fenton et al. (2010), girls with lower BMI were more likely to describe themselves as 'about right'; whereas boys were more likely to say they were 'too thin'. Boys with higher BMI scores were more likely to describe themselves as 'about right, whereas girls were likely to state that they were 'too fat'. This could possibly be a result of sociocultural patterns, gender influences (Murnen \& Don, 2012), and media images (Wertheim \& Paxton, 2012).

This study has some limitations and strengths. Firstly, BMI does not asses body fat and muscle, which could help understand the recorded relationship between body satisfaction and BMI. Secondly, body satisfaction was calculated using self-assessment methods, therefore subjective interpretation of questions could influence the results. The key strength of this paper is the demonstration of the importance of body satisfaction, not only among overweight and normal weight, but also in underweight adolescent girls and boys. Prior studies have predominantly examined the association between body satisfaction and overweight or obesity. The other strengths of this study were the use of the cluster sampling method and the inclusion of a large study population. It should also be noted that direct measurements of weight and height used in our research allowed for accurate BMI calculations.

The results obtained in the present study extend the knowledge of the relationship between body satisfaction and BMI status. Our findings indicated that, in relation to gender, BMI status can be associated with different body satisfaction in adolescents. Due to the fact that underweight girls and boys have high body 
satisfaction, it can be supposed that this can lead to behaviors aimed at maintaining low body weight by adolescents and in turn, this may cause negative health consequences. On the other hand, underweight adolescents who have been shown to have higher body satisfaction, engaged in healthy weight control behaviors more often than their overweight peers (Lampard et al., 2016). This should be taken into consideration in designing programs aimed at preventing obesity, underweight, and improving body image. In overweight boys and girls, interventions aimed at improving body satisfaction may reflect in positive health behaviors and may also affect body mass reduction. During interventions in underweight adolescents (especially females), participants should learn about the negative physical and psychological consequences of being underweight and how to maintain normal body weight through healthy weight control behaviors. Additionally, when educating adolescents about health behaviors we should focus not only on weight status but also implement a holistic approach.

\section{References}

Ahluwalia N., Dalmasso P., Rasmussen M., Lipsky L., Currie C., Haug E., ... Cavallo F. (2015). Trends in overweight prevalence among 11-, 13- and 15-year-olds in 25 countries in Europe, Canada and USA from 2002 to 2010. The European Journal of Public Health, 25, 28-32. https://doi.org/10.1093/eurpub/ckv016

Antal M., Péter S., Biró L., Nagy K., Regöly-Mérei A., Arató G., ... Martos É. (2009). Prevalence of underweight, overweight and obesity on the basis of body mass index and body fat percentage in Hungarian schoolchildren: Representative survey in metropolitan elementary schools. Annals of Nutrition \& Metabolism, 54, 171-176. https:/ / doi. org/10.1159/000217813

Cash T. F. (2011). Cognitive-behavioral perspectives on body image. In T. F. Cash \& L. Smolak (Eds.), Body image: A handbook of science, practice, and prevention (pp. 39-47). New York, NY: Guilford Press.

Chen G., Guo G., Gong J., \& Xiao S. (2015). The association between body dissatisfaction and depression: An examination of the moderating effects of gender, age, and weight status in a sample of Chinese adolescents. Journal of Psychologists and Counsellors in Schools, 25, 245-260.

https: / / doi.org/10.1017/jgc.2015.6

Cole T. J., Bellizzi M. C., Flegal K. M., \& Dietz W. H. (2000). Establishing a standard definition for child overweight and obesity worldwide: International survey. BMJ, 320, 1240-1243. https: / / doi.org/10.1136/bmj.320. 7244.1240

Cole T. J., Flegal K. M., Nicholls D., \& Jackson A. A. (2007). Body mass index cut offs to define thinness in children and adolescents: International survey. BMJ, 335, 194. https://doi.org/10.1136/bmj.39238.399444.55

de Sousa P. M. (2008). Body-image and obesity in adolescence: A comparative study of social-demographic, psychological, and behavioral aspects. The Spanish Journal of Psychology, 11, 551-563.

Duncan M. J., Al-Nakeeb Y., \& Nevill A. M. (2013). Establishing the optimal body mass index-body esteem relationship in young adolescents. BMC Public Health, 13, 662. https:/ / doi.org/10.1186/1471-2458-13-662

Eidsdottir S. T., Kristjansson A. L., Sigfusdottir I. D., Garber C. E., \& Allegrante J. P. (2014). Association between higher BMI and depressive symptoms in Icelandic adolescents: The mediational function of body image. The European Journal of Public Health, 24, 888-892. https://doi.org/10.1093/eurpub/ckt180

Eisenberg M. E., Wall M., \& Neumark-Sztainer D. (2012). Muscle-enhancing behaviors among adolescent girls and boys. Pediatrics, 130, 1019-1026. https://doi.org/10.1542/ peds.2012-0095

Fenton C., Brooks F., Spencer N. H., \& Morgan A. (2010). Sustaining a positive body image in adolescence: An assets-based analysis. Health $\&$ Social Care in the Community, 18, 189-198.

Freedman D. S., Khan L. K., Serdula M. K., Dietz W. H., Srinivasan S. R., \& Berenson G. S. (2005). The relation of childhood BMI to adult adiposity: The Bogalusa heart study. Pediatrics, 115, 22-27.

Hargreaves D. A., \& Tiggemann M. (2006). 'Body image is for girls' a qualitative study of boys' body image. Journal of Health Psychology, 11, 567-576. https: / / doi.org/10.1177/ 1359105306065017

Holsen I., Carlson Jones D., \& Skogbrott Birkeland M. (2012). Body image satisfaction among Norwegian adolescents and young adults: A longitudinal study of the influence of interpersonal relationships and BMI. Body Image, 9, 201-208. https:/ / doi.org/10.1016/j.bodyim. 2012.01.006

Kantanista A., \& Osiński W. (2014). Underweight in 14 to 16 year-old girls and boys: Prevalence and associations with physical activity and sedentary activities. Annals of Agricultural and Environmental Medicine, 21, 114-119. Retrieved from http:/ /aaem.pl/abstracted.php? level $=4 \&$ id_issue $=872203 \& \mathrm{dz}=\mathrm{s} 6$

Kantanista A., Osiński W., Borowiec J., Tomczak M., \& Król-Zielińska M. (2015). Body image, BMI, and physical activity in girls and boys aged 14-16 years. Body Image, 15, 40-43. https://doi.org/10.1016/j.bodyim.2015.05.001

Kołoło H., Guszkowska M., Mazur J., \& Dzielska A. (2012). Self-efficacy, self-esteem and body image as psychological determinants of 15-year-old adolescents' physical activity levels. Human Movement, 13, 264-270. https://doi.org/ 10.2478/v10038-012-0031-4

Kostanski M., Fisher A., \& Gullone E. (2004). Current conceptualisation of body image dissatisfaction: Have we got it wrong? Journal of Child Psychology and Psychiatry, 45, 1317-1325. https://doi.org/10.1111/j.1469-7610. 2004.00315.x

Lampard A. M., Maclehose R. F., Eisenberg M. E., Larson N. I., Davison K. K., \& Neumark-Sztainer D. (2016). Adolescents who engage exclusively in healthy weight control behaviors: Who are they? International Journal of Behavioral Nutrition and Physical Activity, 13, 5. https: / /doi. org/10.1186/s12966-016-0328-3 
Lazzeri G., Rossi S., Pammolli A., Pilato V., Pozzi T., \& Giacchi M. V. (2008). Underweight and overweight among children and adolescents in Tuscany (Italy). Prevalence and short-term trends. Journal of Preventive Medicine and Hygiene, 49, 13-21.

Lubans D. R., \& Cliff D. P. (2011). Muscular fitness, body composition and physical self-perception in adolescents. Journal of Science and Medicine in Sport / Sports Medicine Australia, 14, 216-221. https://doi.org/10.1016/j.jsams. 2010.10.003

Mikolajczyk R. T., Maxwell A. E., El Ansari W., Stock C., Petkeviciene J., \& Guillen-Grima F. (2010). Relationship between perceived body weight and body mass index based on self-reported height and weight among university students: A cross-sectional study in seven European countries. BMC Public Health, 10, 40-51. https://doi.org/10.1186/1471-2458-10-40

Murnen S. K., \& Don B. P. (2012). Body image and gender role. In T. F. Cash (Ed.), Encyclopedia of body image and human appearance (pp. 128-134). San Diego, CA: Academic Press.

Muth J. L., \& Cash T. F. (1997). Body-image attitudes: What difference does gender make. Journal of Applied Social Psychology, 27, 1438-1452. https://doi.org/10.1111/j. 1559-1816.1997.tb01607.x

Neumark-Sztainer D., Goeden C., Story M., \& Wall M. (2004). Associations between body satisfaction and physical activity in adolescents: Implications for programs aimed at preventing a broad spectrum of weight-related disorders. Eating Disorders, 12, 125-137. https: / / doi.org/ 10.1080/10640260490444989

Neumark-Sztainer D., Paxton S. J., Hannan P. J., Haines J., \& Story M. (2006). Does body satisfaction matter? Five-year longitudinal associations between body satisfaction and health behaviors in adolescent females and males. The Journal of Adolescent Health: Official Publication of the Society for Adolescent Medicine, 39, 244-251. https:/ / doi.org/ 10.1016/j.jadohealth.2005.12.001

Neumark-Sztainer D., Story M., Hannan P. J., Perry C. L., \& Irving L. M. (2002). Weight-related concerns and behaviors among overweight and nonoverweight adolescents: Implications for preventing weight-related disorders. Archives of Pediatrics \& Adolescent Medicine, 156, 171-178. https:/ / doi.org/10.1001/archpedi.156.2.171

Orbach I., \& Mikulincer M. (1998). The body investment scale: Construction and validation of a body experience scale. Psychological Assessment, 10, 415-425. https: / doi. org $/ 10.1037 / 1040-3590.10 .4 .415$

Roh L., Braun J., Chiolero A., Bopp M., Rohrmann S., Faeh D., \& For The Swiss National Cohort Study Group (2014). Mortality risk associated with underweight: A census-linked cohort of 31,578 individuals with up to 32 years of follow-up. BMC Public Health, 14, 371. https:/ / doi.org/10.1186/1471-2458-14-371

Sabeti F., \& Gorjian Z. (2013). The relationship between the satisfaction of body image and self-esteem among obese adolescents in Abadan, Iran. Iranian Journal of Diabetes and Obesity, 5, 126-131.

Smolak L. (2004). Body image in children and adolescents: Where do we go from here? Body Image, 1, 15-28. https://doi.org/10.1016/S1740-1445(03)00008-1

U.S. Department of Health and Human Services (2010). The surgeon general's vision for a healthy and fit nation. Rockville, MD: HHS, Public Health Service, Office of the Surgeon General (US).

Wertheim E. H., \& Paxton S. J. (2012). Body image development - adolescent girls. In T. F. Cash (Ed.), Encyclopedia of body image and human appearance (pp. 187-193). San Diego, CA: Academic Press.

Wilkosz M. E., Chen J. L., Kenndey C., \& Rankin S. (2011). Body dissatisfaction in California adolescents. Journal of the American Academy of Nurse Practitioners, 23, 101-109. https:/ / doi.org/10.1111/j.1745-7599.2010.00586.x

Zach S., Zeev A., Dunsky A., Goldbourt U., Shimony T., Goldsmith R., \& Netz Y. (2013). Perceived body size versus healthy body size and physical activity among adolescents - Results of a national survey. European Journal of Sport Science, 13, 723-731. https:/ / doi.org/10.1080/ 17461391.2013.771382 